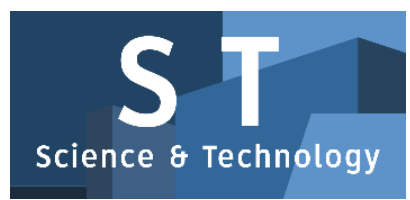

PAPER - OPEN ACCESS

\title{
Kajian Metode Eoq (Economic Order Quantity) Pada Model Persediaan Deterministik Dengan Perubahan Harga Dalam Pengendalian Persediaan
}
Author
: Tri Hardianti
DOI
: 10.32734/st.v1i1.185
Electronic ISSN
: 2654-7091
Print ISSN
: 2654-7083

Volume 1 Issue 1 - 2018 TALENTA Conference Series: Science \& Technology (ST)

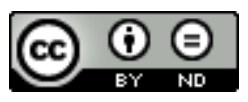

This work is licensed under a Creative Commons Attribution-NoDerivatives 4.0 International License.

Published under licence by TALENTA Publisher, Universitas Sumatera Utara
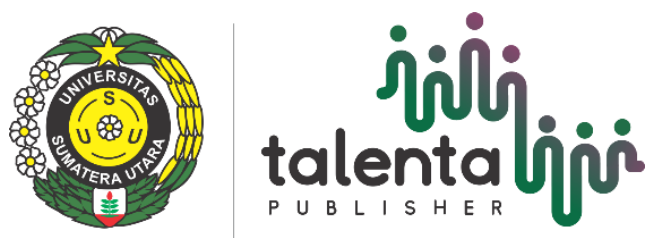


\title{
Kajian Metode Eoq (Economic Order Quantity) pada Model Persediaan Deterministik Dengan Perubahan Harga Dalam Pengendalian Persediaan
}

\author{
Tri Hardianti ${ }^{*}$, Faigiziduhu Bu'ulolo ${ }^{\mathrm{a}}$, Esther Nababan ${ }^{\mathrm{a}}$ \\ Fakultas Matematika dan Ilmu Pengetahuan Alam, Universitas Sumatera Utara, Medan 20155, Indonesia
}

tri3.hardianti@gmail.com, buulolo@usu.ac.id ; esther@usu.ac.id

\begin{abstract}
Abstrak
Persediaan merupakan salah satu unsur yang paling aktif dalam operasi perusahaan yang secara terus- menerus diperoleh, diubah yang kemudian dijual kembali. Metode Economic Order Quantity (EOQ) merupakan metode yang digunakan untuk menemukan jumlah pesanan yang ekonomis, yaitujumlah pesanan yang memenuhi total biaya persediaan minimal dengan mempertimbangkan biaya pemesanan dan penyimpanan. Persediaan deterministik merupakan metode yang digunakan untuk meminimalkan total biaya pembelian dan penyimpanan. Dalam penelitian ini metode EOQ dikaji ke dalam bentuk model persediaan deterministik dengan perubahan harga. Metode yang digunakan adalah metode EOQ. Metode EOQ kemudian digunakan pada model persediaan deterministik dengan perubahan harga. Model tersebut diaplikasikan pada sebuah contoh kasus dengan model special sale price yang memperoleh penghematan biaya sebesar 40.000 dan special order cost saving sebesar 133.559.888,5 dengan frekuensi pemesanan 18,5 per tahun. Model tersebut dapat digunakan pada perusahaan untuk meminimalkan biaya penyimpanan dan pembelian. Pada saat-saat tertentu perusahaan memperoleh keuntungan lebih besar dengan biaya pembelian dan penyimpanan yang lebih kecil.
\end{abstract}

Kata Kunci; Persediaan; Economic Order Quantity; Persediaan Deterministik; Perubahan Harga

\section{Pendahuluan}

Setiap perusahaan baik itu perusahaan jasa ataupun perusahaan manufaktur, selalu memerlukan persediaan. Tanpa adanya persediaan, setiap pengusaha akan dihadapkan pada risiko bahwa perusahaannya pada suatu waktu tidak dapat memenuhi keinginan para pelanggannya. Hal ini bisa saja terjadi, karena tidak selamanya barang-barang atau jasajasa tersedia pada setiap saat, yang berarti pula bahwa pengusaha akan kehilangan kesempatan memperoleh keuntungan yang seharusnya didapatkan. Jadi, persediaan sangat penting untuk setiap perusahaan, baik yang menghasilkan suatu barang maupun jasa.

Persediaan merupakan salah satu unsur yang paling aktif dalam operasi perusahaan yang secara terus- menerus diperoleh, diubah yang kemudian dijual kembali. Sebagian besar sumber-sumber perusahaan juga sering dikaitkan di dalam persediaan yang akan digunakan dalam perusahaan pabrik. Nilai persediaan harus dicatat, digolong-golongkan menurut jenisnya yang kemudian dibuat perincian masing- masing barangnya dalam suatu periode yang bersangkutan.

Metode EOQ adalah volume atau jumlah pembelian yang paling ekonomis untuk dilakukan pada setiap kali pembeliaan.Metode EOQ (Economic Order Quantity)dalam kuantitas pesanan ekonomis merupakan salah satu model klasik yang pertama kali diteliti dan juga diperkenalkan oleh Ford W. Harris pada tahun 1915. Teknik pengendalian persediaan metode EOQ banyak dipergunakan sampai saat ini karena mudah dalam penggunaannya. Metode ini digunakan untuk menghitung minimalisasi total biaya persediaan berdasarkan persamaan tingkat atau titik equilibrium kurva biaya simpan dan biaya pesan. 
Model persediaan deterministik merupakan model yang menganggap semua variabel telah diketahui dengan pasti. Tujuan penelitian ini adalah untuk mengkaji lebih dalam mengenai penggunaan metode EOQ (Economic Order Quantity) dalam persediaan deterministik dengan perubahan harga dalam pengendalian persediaan.

\section{Landasan Teori}

\subsection{Economic Order Quantity (EOQ)}

Jumlah pemesanan yang dapat meminimumkan total biaya persediaan disebut Economic Order Quantity (EOQ). Secara klasik model persediaan dianggap ideal, di mana $\mathrm{Q}$ adalah jumlah pembelian dan ketika pesanan diterima jumlah persediaan sama dengan Q. Dengan tingkat penggunaan tetap, persediaan akan habis dalam waktu tertentu dan ketika persediaan hanya tinggal sebanyak kebututhan selama tenggang waktu pemesanan kembali (reorder point $=$ ROP) harus dilakukan.

Jika tidak terjadi kekurangan persediaan (stockout), maka total biaya persediaan per tahun ditunjukkan dalam Gambar 1 dengan menggunakan rumus sebagai berikut:

Total biaya $=$ biaya pembelian + biaya pemesanan + biaya simpan

$$
\begin{aligned}
& T C(Q)=P_{C}+H_{C}+O_{C} \\
& T C(Q)=P D+P F \frac{Q}{2}+C \frac{R}{Q} \\
& \text { di mana: }
\end{aligned}
$$

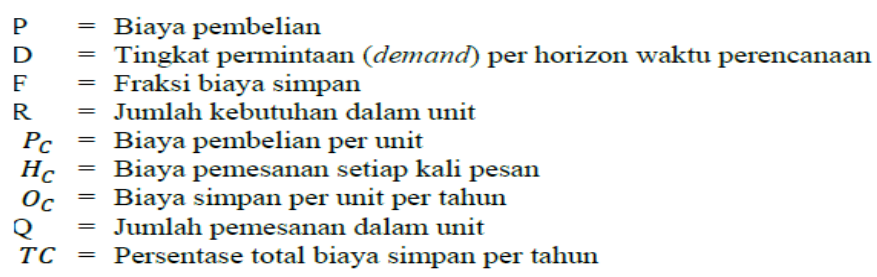

Total biaya pembelian adalah biaya pembelian per unit (Pc) dikalikan dengan jumlah kebutuhan (R). Total biaya pemesanan adalah biaya biaya pemesanan setiap kali pesan $(\mathrm{Hc})$ dikali dengan frekuensi pemesanan selama satu tahun ( R). Total biaya simpan adalah biaya simpan per unit (OC) dikali dengan Q rata-rata persediaan (Q/2). Jumlah dari ketiga jenis biaya tersebut (biaya pembelian, biaya pemesanan, dan biaya simpan) adalah total biaya persediaan per tahun.

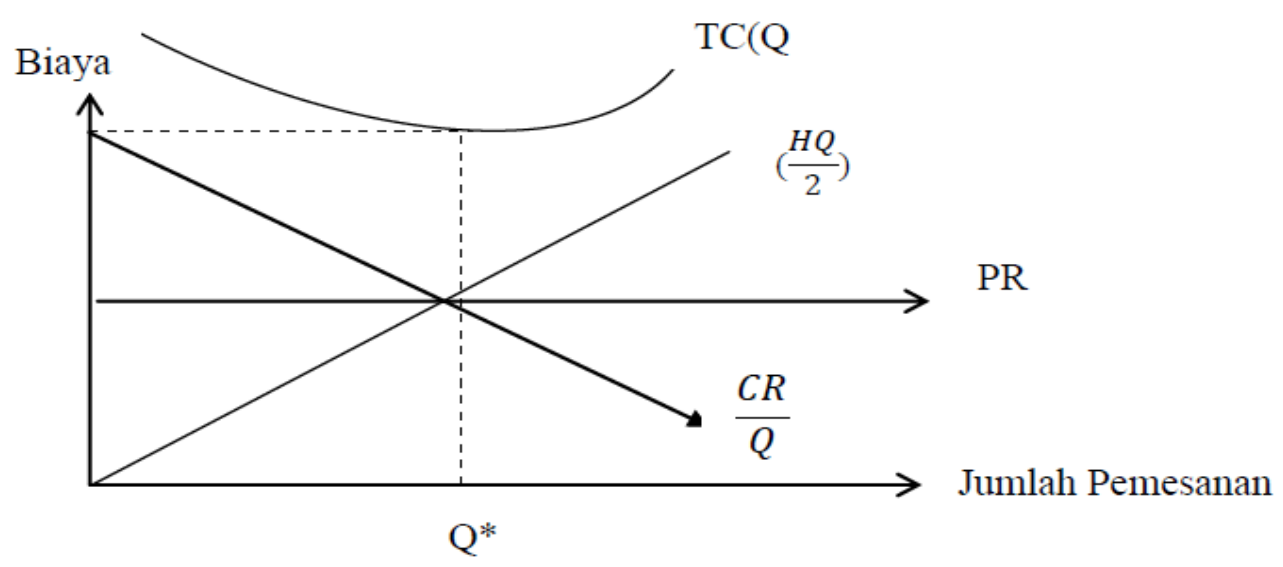

Gambar 1: Total Biaya Persediaan 


\subsection{Model Persediaan Deterministik Dengan Perubahan Harga}

\subsubsection{Harga Khusus}

Seorang supplier menawarkan harga diskon dalam waktu tertentu. Apabila perusahaan tertarik terhadap tawaran ini, maka akan ada pesanan tambahan. Hal ini berarti manajemen harus menentukan kembali jumlah optimum pemesanan yang harus dilakukan [5].

Kenaikan harga yang disebabkan oleh perubahan eksternal perusahaan tersebut, biasanya sudah dapat diprediksikan sebelumnya, sehingga pihak pembeli akan melakukan penyesuaian terhadap barang pesanannya. Hal inilah yang menyebabkan munculnya model known price increase [4].

\subsubsection{Model Special Sale Price}

Asumsi bahwa ketika suatu order/pesanan sedang dilakukan, maka ditemukan bahwa supplier untuk sementara mengurangi harga item tersebut, hal ini berlaku hanya sekali itu. Pada saat yang regular harga $\mathrm{P}$, tetapi saat pembelian tersebut mendapatkan pengurangan harga menjadi $\mathrm{p}$ - dtiap unitnya, di mana $\mathrm{d}$ adalah unit pengurangan yang terjadi. Apabila hari yang temporer tersebut sudah berlalu, maka harga item akan kembali normal ke harga P. Jumlah pemesanan sebelum dan setelah pengurangan harga adalah:

$$
Q=\sqrt{\frac{2 C R}{P F}}
$$

Untuk memperoleh pesanan ukuran khusus yang optimal, adalah diperlukan untuk memaksimalkan perbedaan biaya sepanjang waktu tersebut selama periode $Q / R_{R}$ dengan dan tanpa order/pesanan yang khusus tersebut [4].Total biaya selama periode $Q /{ }_{R}$ atau pesanan khusus menggunakan harga pembelian per unit $P-d$, adalah sebagai berikut:

Total biaya $=$ biaya pembelian + biaya simpan + biaya pemesanan

$$
\begin{aligned}
& T C_{S}=(P-d) Q+\frac{Q}{2}(P-d) \frac{T Q}{R}+C \\
& T C_{S}=(P-d) Q+\frac{(P-d) T Q^{2}}{2 R}+C
\end{aligned}
$$

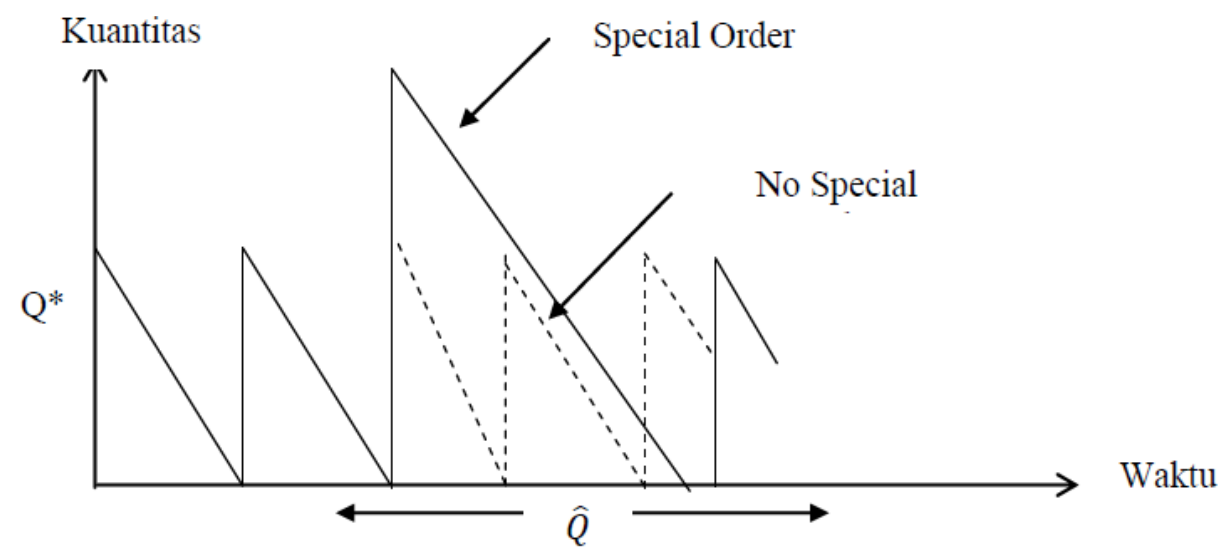

Gambar 2: Model Special Sale Price 
Jika tidak ada pesanan khusus yang dilakukan selama Q/R total biaya pesanan pertama adalah menggunakan $\mathrm{P}-\mathrm{d}$ dan semua pesanan berikutnya menggunakan harga $\mathrm{P}$, adalah sebagai berikut[5]:

$$
\begin{gathered}
T C_{n}=(P-d) Q^{*}+P\left(Q-Q^{*}\right)+\frac{Q}{2}(P-d) \frac{T Q^{*}}{2 R}+\frac{Q^{*}}{2} P T \frac{\left(Q-Q^{*}\right)}{R}+\frac{C Q}{Q^{*}} \\
T C_{n}=P Q-d Q^{*}-\frac{d T\left(Q^{*}\right)^{2}}{2 R}+\frac{P T Q^{*} Q}{2 R}+\frac{C Q}{Q^{*}}
\end{gathered}
$$

di mana:

$\mathrm{d} \quad=$ Potongan harga per unit

$\mathrm{P} \quad$ = Harga per unit sebelum diskon

$\mathrm{C} \quad=$ Biaya pesan setiap kali pemesanan

$\mathrm{T} \quad=$ Persentase biaya simpan

$\mathrm{R}=$ Jumlah unit kebutuhan satu periode

$Q^{*}=$ Unit EOQ

$Q \quad=$ Jumlah unit pesanan khusus

Apabila pemesanan barang dilakukan sebelum jadwal yang biasanya dilakukan (biasanya jadwal pesan dilakukan pada saat gudang tidak ada barang, jika lead time $=0$ ), maka kuantitas pemesanan yang optimal adalah sebagai berikut

$$
Q^{*}=\frac{d R}{(P-d) F}+\frac{P Q^{*}}{P-d}
$$

dengan penghematan biaya sebesar:

$$
g^{*}=\frac{C(P-d)}{P}\left(\frac{\hat{Q}^{*}}{Q^{*}}-1\right)^{2}
$$

\section{Pembahasan}

\subsection{Model Economic Order Quantity (EOQ)}

Untuk memperoleh nilai Q yang optimal dengan tujuan meminimumkan biaya total persediaan, Persamaan 1 harus di diferensialkan terhadap Q kemudian dibuat nol. Akan diperoleh nilai Q optimal yang dinotasikan dengan Q*. Di mana Q* merupakan nilai dari Economic Order Quantity (EOQ).

$$
\begin{aligned}
& T C(Q)=P_{C}+H_{C}+O_{C} \\
& T C(Q)=P D+P F \frac{Q}{2}+C \frac{R}{Q} \\
& \frac{d T C(Q)}{d Q}=0 \\
& \frac{d\left(P_{C}+H_{C}+O_{C}\right)}{d Q}=0 \\
& \frac{d\left(P D+P F \frac{Q}{2}+C \frac{R}{Q}\right)}{d Q}=0 \\
& \frac{d(P D)}{d Q}+\frac{d\left(P F \frac{Q}{2}\right)}{d Q}+\frac{d\left(C \frac{R}{Q}\right)}{d Q}=0 \\
& 0+\frac{P F}{2}+\left(-\frac{C R}{\left(Q^{*}\right)^{2}}\right)=0 \\
& \frac{P F}{2}-\left(\frac{C R}{\left(Q^{*}\right)^{2}}\right)=0 \\
& \frac{P F}{2}=\frac{C R}{\left(Q^{*}\right)^{2}} \\
& \left(Q^{*}\right)^{2}=\frac{2 C R}{P F}
\end{aligned}
$$




$$
Q^{*}=\sqrt{\frac{2 C R}{P F}}=\text { EconomicOrderQuantity }(E O Q)
$$

\subsection{Model Persediaan Deterministik Dengan Perubahan Harga}

\subsubsection{Model Special Sale Price}

Untuk menemukan yang optimal pada order/pesanan dengan ukuran khusus maka harus dihitung perbedaan secara keseluruhan biaya-biaya antara kedua kondisi tersebut TCn - TCs, sehingga jika fungsi yang diperoleh itu kemudian dilakukan derivative yang pertama lalu dibuat sama dengan nol akan diperoleh sebagai berikut:

$$
\begin{aligned}
& g=T C_{n}-T C_{s}=\text { specialordercostsaving } \\
& =\left(d+\frac{2 C}{Q^{*}}\right) Q-\frac{(P-d) F Q^{2}}{2 R}-d Q^{*}-\frac{d F\left(Q^{*}\right)^{2}}{2 R}-C \\
& \frac{d g}{d Q}=d+\frac{2 C}{Q^{*}}-\frac{(P-d) F Q}{R}=0 \\
& Q=\frac{d R}{(P-d) F}+\frac{P Q^{*}}{P-d}=\text { Optimumspecialordersice }
\end{aligned}
$$

Dari persamaan di atas dapat diketahui bahwa jika harga potongan per satuan unit adalah nol (d=0), akan mengakibatkan pengurangan terhadap EOQ dan menyebabkan penghematan biaya atau special order cost saving menjadi nol $(\mathrm{g}=0)$. Dengan menggunakan $\mathrm{Q}$ dengan $\mathrm{Q} *$ di dalam persamaan special order cost saving dengan notasi $\mathrm{g}$, maka akan diperoleh sebagai berikut:

$$
\begin{aligned}
g^{*}= & \left(d+\frac{2 C}{Q^{*}}\right)\left[\frac{d R}{(P-d) F}+\frac{P Q^{*}}{P-d}\right]-\frac{(P-d)\left[\frac{d R}{(P-d) F}+\frac{P Q^{*}}{P-d}\right]^{2}}{2 R}-d Q^{*}-\frac{d F\left(Q^{*}\right)^{2}}{2 R}-C \\
g^{*}= & \left(d+\frac{2 C}{Q^{*}}\right)\left[\frac{d R}{(P-d) F}\right]+\left(d+\frac{2 C}{Q^{*}}\right)\left[\frac{P Q^{*}}{P-d}\right] \\
& -\frac{(P-d) F\left[\frac{(d R)^{2}}{(P-d)^{2} F^{2}}+\frac{\left(P Q^{*}\right)^{2}}{(P-d)^{2}}+2 \frac{d R P Q^{*}}{(P-d)^{2} F}\right]}{2 R}-d Q^{*}-\frac{d F\left(Q^{*}\right)^{2}}{2 R}-C \\
g^{*}= & {\left[\frac{d^{2} R}{(P-d) F}+\frac{2 d R C}{Q^{*}(P-d) F}\right]+\left[\frac{d P Q^{*}}{P-d}+\frac{2 C P Q^{*}}{(P-d)^{2} Q^{*}}\right] } \\
& -\frac{\left[\frac{(d R)^{2}}{(P-d) F}+\frac{\left(P Q^{*}\right)^{2} F}{(P-d)}+2 \frac{d R P Q^{*}}{(P-d)}\right]}{2 R}-d Q^{*}-\frac{d F\left(Q^{*}\right)^{2}}{2 R}-C \\
g^{*}= & {\left[\frac{\left.d^{2} R Q^{*}+2 d R C+d P F\left(Q^{*}\right)^{2}+2 C P F Q^{*}\right]}{(P-d) F Q^{*}}\right] } \\
& -\frac{\left[\frac{(d R)^{2}+\left(P Q^{*}\right)^{2} F^{2}+2 d R P F Q^{*}}{(P-d) F}\right]}{2 R}-d Q^{*}-\frac{d F\left(Q^{*}\right)^{2}}{2 R}-C \\
g^{*}= & \frac{1}{2 R(P-d) F Q^{*}}\left[2 d^{2} P^{2} Q^{*}+4 d R^{2} C+2 R d P F\left(Q^{*}\right)^{2}+4 R C P F Q^{*}\right] \\
& -\frac{1}{2 R(P-d) F Q^{*}}\left[(d R)^{2} Q^{*}+\left(P Q^{*}\right)^{2} F^{2} Q^{*}+2 d R P F\left(Q^{*}\right)^{2}\right]
\end{aligned}
$$




$$
\begin{gathered}
-\frac{1}{2 R(P-d) F Q^{*}}\left[2 R(P-d) F d\left(Q^{*}\right)^{2}+(P-d) d F^{2}\left(Q^{*}\right)^{2}-2 R C(P-d) F Q^{*}\right] \\
g^{*}=\frac{1}{2 R(P-d) F Q^{*}}\left[d^{2} R^{2} Q^{*}+4 d R^{2} C+4 R C P F Q^{*}-(P F)^{2}\left(Q^{*}\right)^{3}\right] \\
-\frac{1}{2 R(P-d) F Q^{*}}\left[2 R(P-d) F d\left(Q^{*}\right)^{2}+(P-d) d F^{2}\left(Q^{*}\right)^{2}-2 R C(P-d) F Q^{*}\right] \\
g^{*}=\frac{C(P-d)}{P}\left(\frac{Q}{Q^{*}}-1\right)^{2}(10)
\end{gathered}
$$

\subsubsection{Pembahasan Contoh Kasus}

Sebuah toko mainan anak-anak harus merencanakan persediaan boneka. Empat jenis boneka dipesan dari supplier boneka yaitu boneka Tazmania, boneka Hello Kitty, boneka Teddy Bear, dan boneka Lumba-lumba. Supplier boneka

\begin{tabular}{|c|c|c|c|c|c|c|c|}
\hline Tazmania & & Hello Kitty & & Teddy Bear & & Lumba-Lu & \\
\hline $\begin{array}{l}\text { Jumlah } \\
\text { Pembelian } \\
\text { (Unit) }\end{array}$ & $\begin{array}{l}\text { Harga } \\
(\mathrm{Rp})\end{array}$ & $\begin{array}{l}\text { Jumlah Pembelian } \\
\text { (Unit) }\end{array}$ & $\begin{array}{l}\text { Harga } \\
\text { (Rp) }\end{array}$ & $\begin{array}{l}\text { Jumlah } \\
\text { Pembelian } \\
\text { (Unit) }\end{array}$ & $\begin{array}{l}\text { Harga } \\
(\mathrm{Rp})\end{array}$ & $\begin{array}{l}\text { Jumlah } \\
\text { Pembelian } \\
\text { (Unit) }\end{array}$ & $\begin{array}{l}\text { Harga } \\
(\mathrm{Rp})\end{array}$ \\
\hline $1-49$ & 30.000 & $1-999$ & 5.000 & $1-99$ & 20.000 & $1-499$ & 5.000 \\
\hline $50-99$ & 27.000 & $\begin{array}{l}1,000- \\
1.999\end{array}$ & 4.800 & $100-999$ & 19.000 & $500-999$ & 4.500 \\
\hline $100-199$ & 25.000 & $\geq 2.000$ & 4.750 & $\geq 1.000$ & 18.000 & $\geq 1.000$ & 3.900 \\
\hline$\geq 200$ & 21.000 & & & & & & \\
\hline
\end{tabular}
memberikan kebijakan tentang harga pembelian untuk masing-masing boneka seperti yang ditunjukkan pada Tabel berikut:

Tabel 1: Struktur Potongan Harga Dari Supplier

Jika mempertimbangkan harga/unit, maka ada kecenderungan perusahaan akan membeli boneka dalam jumlah yang besar dengan harapan memperoleh keuntungan dan discount. Ada biaya yang juga meningkat jika dilakukan pembelian dalam jumlah besar, yaitu biaya simpan. Maka pembelian dalam jumlah yang besar tidak dapat dipastikan bisa meminimumkan total biaya pengadaan persediaan. Biaya pesan setiap kali pesan $(C)=\mathrm{Rp} 40.000$. Biaya simpan (H) $20 \%$ dari harga barang yang disimpan. Permintaan boneka Tazmania adalah 1.000 unit per tahun, boneka Hello Kitty adalah 5.000 unit per tahun, boneka Teddy Bear adalah 3.000 unit per tahun, dan boneka Lumba-lumba adalah 10.000 unit per tahun.

Solusi:

Tabel 2: Hasil Perhitungan Jumlah Pesanan Ekonomis

\begin{tabular}{cccccc}
\hline Kisaran & $\mathrm{Q}_{\mathrm{A}}$ & $\mathrm{Q}_{\mathrm{B}}$ & $\mathrm{Q}_{\mathrm{C}}$ & $\mathrm{Q}_{\mathrm{D}}$ & Valid/Tidak \\
\hline I & 49 & 246 & 148 & 492 & Tidak valid \\
II & 50 & 248 & 149 & 497 & Tidak valid \\
III & 51 & 255 & 153 & 510 & Valid \\
IV & 52 & 262 & 157 & 523 & Tidak valid \\
\hline
\end{tabular}




\begin{tabular}{cccccc}
\hline V & 53 & 266 & 160 & 533 & Tidka valid \\
VI & 54 & 269 & 161 & 538 & Tidak valid \\
\hline
\end{tabular}

Tabel 3: Hasil Perhitungan Biaya Pengadaaan Persediaan

\begin{tabular}{cccccccccc}
\hline$Q_{A}^{*}$ & $Q_{B}^{*}$ & $Q_{C}^{*}$ & $Q_{D}^{*}$ & Keterangan & $\begin{array}{c}\text { Biaya } \\
\text { Pesan }\end{array}$ & $\begin{array}{c}\text { Biaya } \\
\text { Simpan }\end{array}$ & $\begin{array}{c}\text { Biaya } \\
\text { Pembelian }\end{array}$ & $\begin{array}{c}\text { Biaya } \\
\text { Total }\end{array}$ \\
\hline 51 & 255 & 153 & 510 & JPE & $784.313,72$ & 785.400 & 154.000 .000 & $155.569 .713,70$ \\
100 & 500 & 300 & 1.000 & PB & $400.000,00$ & 1.460 .000 & 146.000 .000 & $147.860 .000,00$ \\
200 & 1.000 & 600 & 2.000 & PB & $200.000,00$ & 2.820 .000 & 141.000 .000 & $144.020 .000,00$ \\
334 & 1.667 & 1.000 & 3.334 & PB & $119.760,48$ & 4.609 .200 & 138.000 .000 & $142.728 .960,48$ \\
400 & 2.000 & 1.200 & 4.000 & PB & $100.000,00$ & 4.587 .075 & 137.750 .000 & $142.437 .075,00$ \\
\hline
\end{tabular}

Keterangan: JPE=jumlah pesan ekonomis valid, $\mathrm{PB}=$ jumlah pesanan Price Break

Tabel 4: Hasil Perhitungan Total Harga

\begin{tabular}{cccccc}
\hline Kisaran & $\mathrm{C}$ & $\mathrm{P}$ & $\mathrm{TC}$ & $\mathrm{TC}_{\mathrm{n}}$ & $\mathrm{G}$ \\
\hline III & 40.000 & 154.000 .000 & $155.569,713,70$ & $149.226 .322 .224,35$ & $149.070 .752 .510,64$ \\
IV & 40.000 & 146.000 .000 & $147.860 .000,00$ & $145.125 .386 .298,32$ & 144.977 .526 .298 .32 \\
V & 40.000 & 141.000 .000 & $144.020 .000,00$ & $142.695 .425 .523,66$ & $142.551 .405 .523,66$ \\
VI & 40.000 & 138.000 .000 & $142.728 .960,48$ & $141.681 .900 .996,97$ & $141.894 .057 .947,60$ \\
VII & 40.000 & 137.750 .000 & $142.437 .075,00$ & $118.764 .049 .889,11$ & $118.621 .612 .814,11$ \\
\hline
\end{tabular}

Tabel 5: Model perhitungan special sale price

\begin{tabular}{crrrr}
\hline Kisaran & \multicolumn{1}{c}{$Q_{T}^{*}$} & \multicolumn{1}{c}{$Q_{T}^{*}$} & $\mathrm{~g}$ & \multicolumn{1}{c}{$\mathrm{G}^{*}$} \\
\hline III & 969 & 969 & $149.083 .767 .648,77$ & 40.000 \\
IV & 1.900 & 1.900 & $144.987 .537 .642,82$ & 40.000 \\
V & 3.800 & 3.800 & $142.551 .193 .718,32$ & 40.000 \\
VI & 6.335 & 6.335 & $140.896 .320 .801,48$ & 40.000 \\
VII & 7.600 & 7.600 & $133.559 .152 .888,5$ & 40.000 \\
\hline
\end{tabular}

Dari hasil analisis di atas pada Tabel 2 terlihat bahwa beberapa kisaran perhitungan jumlah pesanan ekonomis tidak valid. Sedangkan pada kisaran III jumlah pesanan ekonomisnya valid. Pada Tabel 3 diperlihatkan hasil perhitungan biaya pengadaan persediaan dengan memperoleh biaya pesan, biaya simpan, biaya pembelian dan biaya total. Pada tabel 4 diperlihatkan hasil perhitungan total harga. Terlihat pada kisaran VII diperoleh harga minimum untuk setiap kali pemesanan. Pada Tabel 5 merupakan hasil perhitungan special sale price. Pada Tabel 5 dapat dilihat bahwa ternyata keputusan jumlah pesanan adalah pada jumlah pesanan yang terakhir yaitu kisaran VII karena total biayanya lebih minimum dibandingkan yang lainnya. Jumlah pesanan tersebut adalah 7.600 unit keseluruhan boneka, dengan masing-masing 54 unit untuk A (boneka Tazmania), 269 unit untuk B (boneka Hello Kitty), 162 unit untuk C (boneka Teddy Bear) dan 539 unit untuk D (boneka Lumba-Lumba). Setiap kali pesan memperoleh potongan harga sebesar 40.000 , dengan special order cost saving $(\mathrm{g})$ sebesar $133.559 .888,5$, dan frekuensi pemesanannya $\mathrm{F} \frac{D A}{Q A}=\frac{1000}{5}=18,5$ kali per tahun. 


\section{Kesimpulan}

Model persediaan deterministik dengan perubahan harga berdasarkan jumlah merupakan salah satu model persediaan yang digunakan pada saat-saat tertentu. Model ini biasa digunakan oleh perusahaan, penjual dalam kejadian tertentu. Seperti pada perayaan hari valentine, hari besar lebaran, tahun baru dan lain-lain. Model ini digunakan untuk menarik pelanggan dengan memberikan perubahan harga ataupun potongan harga. Begitu juga dengan perusahaan, memberikan keuntungan dalam pengadaan persediaan. Model persediaan ini adalah hasil pengembangan dari model persediaan deterministik dasar dengan kasus perubahan harga dengan multi item persediaan. Dari contoh kasus di atas diperoleh hasil yang mempunyai perubahan harga dari harga sebelumnya, yang mana biaya pembelian dengan metode special sale price lebih minimum dibandingkan dengan metode EOQ (Economic Order Quantity).

\section{Referensi}

[1] Heizer, J. dan Reider, B. 2005.Operations Management.Seventh Edition. Jakarta. Salemba Empat.

[2] Rangkuti, Freddy.1998. Manajemen Persediaan Aplikasi di Bidang Bisnis. Jakarta. PT: Raja Grafindo Persada.

[3] Ristono, Agus. 2009. Manajemen Persediaan. Yogyakarta. Graha Ilmu.

[4] Yamit, Zulian. 1999. Manajemen Persediaan. Yogyakarta.EKONISIA Fakultas Ekonomi UII.

[5] Sianturi, Riris. 2011. Model Persediaan Deterministik Multi Item dan Potongan Harga dan Biaya Pesan. [Skripsi]. Medan. Universitas Sumatera Utara, Program Sarjana Matematika. 